\title{
Preparation and Characterization of Electrochemically Deposited Silicon Films in Ionic Liquid from Polysilicon Byproduct $\mathrm{SiCl}_{4}$
}

\author{
Zhanxia Zhao ${ }^{1}$, Jingjing Liu ${ }^{1}$, Chenglong Zhang ${ }^{2,3 *}$ \\ ${ }^{1}$ Department of Physics, Shanghai University, Shanghai 200444, China \\ ${ }^{2}$ WEEE Research Center of Shanghai Polytechnic University, Shanghai 201209, China \\ ${ }^{3}$ Research Center of Resource Recycling Science and Engineering, Shanghai Polytechnic University, \\ Shanghai 201209, China \\ *E-mail: chenglongzh@sina.com
}

doi: $10.20964 / 2018.09 .51$

Received: 12 May 2018 / Accepted: 2 July 2018 / Published: 5 August 2018

\begin{abstract}
Silicon films were electrodeposited on a titanium plate by using a three-electrode system in a $\mathrm{SiCl}_{4}$ based ionic liquid electrolyte $\left([\mathrm{BMIM}] \mathrm{Tf}_{2} \mathrm{~N}\right)$ under potentiostatic electrolysis conditions avoiding high temperature and a complex operation process. The microstructure of the deposited Si films was studied by Raman spectroscopy for varying deposition temperatures (room temperature, $35^{\circ} \mathrm{C}, 45^{\circ} \mathrm{C}$, and $55^{\circ} \mathrm{C}$ ) and electrolyte mass ratios ([BMIM] $\mathrm{Tf}_{2} \mathrm{~N}$ : propylene carbonate[PC]=1:1, 1:2, 1:3, 1:4). Raman spectra confirmed that the deposited Si films were in an amorphous state. The surface topography was studied by scanning electron microscopy (SEM). Results from Raman spectroscopy and SEM showed that films deposited at room temperature with a mass ratio of 1:3 show the best microstructure and surface topography. Energy dispersive X-ray spectroscopy was used to measure the Si elemental content. The optical and electrical properties of the as-deposited Si films were also investigated by varying the deposition time from $1 \mathrm{~h}$ to $4 \mathrm{~h}$ for an electrolyte mass ratio of $1: 3$ at room temperature. The results indicated that the films exhibit a relatively strong photoluminescence peak at a wavelength of approximately $1135 \mathrm{~nm}$ and that the current-voltage curves for the $\mathrm{Si} / \mathrm{Ti}$ junction show an evident rectifying behavior for a deposition time of $1 \mathrm{~h}$, which indicates that the deposited Si films have good electrical conductivity.
\end{abstract}

Keywords: $\mathrm{SiCl}_{4}$, Electrochemical deposition, Ionic liquid, Photoluminescence, Electrical conductivity

\section{$\underline{\text { FULL TEXT }}$}

(C) 2018 The Authors. Published by ESG (www.electrochemsci.org). This article is an open access article distributed under the terms and conditions of the Creative Commons Attribution license (http://creativecommons.org/licenses/by/4.0/). 